\title{
External and internal environment of higher school: influence on the quality of education
}

\author{
Olga Beketova $^{1, *}$ \\ ${ }^{1}$ Moscow Technological Institute, 199334, Moscow, Russia
}

\begin{abstract}
Education, especially higher education, no doubt, is one of the most important values in the modern world. To imagine the prospects of the nearest and medium-term development of the country, its share in the intellectual world 'coin box', you need to appreciate the state of functioning within it higher education system properly, to assess the impact of external and internal environment on its quality. The existent global changes make it necessary to construct a new model of the learning process, the creation of a qualitatively new education management system, the formation of a new university model that exists in an open information society. Reforming of higher school - is a priority in terms of national interests of Russia, without which it is impossible to create a competitive innovative economy based on knowledge in our country.
\end{abstract}

\section{Introduction}

The problem of education and analysis of the situation in the educational services market is very important and demand issue nowadays. In the modern world, the role of higher education, and all the conditions of achieving it is a major and defining problem. Nowadays, in many countries, a lot of attention and time is paid to the education market analysis, its competition, the underlying mechanisms, the structure, the role of education in the market as a whole are studied. And Russia is not an exception.

Education today is one of the most dynamic and promising emerging sectors of the economy, and the market of educational services is one of the highest in terms of development and growth. According to certain estimates the annual increase of volumes of demand and supply in the educational services in the field of higher education and education in the most rapidly developing countries reaches $10-15 \%$. Peculiarities of the development of education and the very essence of education determine the fact that the educational services market has certain specificity. Educational services market is affected by the same forces as any other market, whether it is the market of goods or services. At the same time, it is the educational services market combines both market and non-market mechanisms of functioning. This is its specificity.

Like any other market participant, higher school operates in close cooperation with the external environment, consisting of three levels: mega -, macro and micro environment.

Significant changes in the global economic space (in mega environment), associated with active processes of globalization and integration of national economics, cause the appearance of extra more complex requirements to the content of training of future specialists. The development of electronic economy, the transition from goods economy to knowledge economy finds direct reflection in the content of the educational process.

Influence of the technological environment is characterized by the development and more efficient use in the production of intelligent technologies, by the significant increase in labour productivity in all the areas without any exception, by the creation of goods and services that mostly suit the individual needs of consumers.

Information environment is one of the most dynamic elements of the mega environment. Its development is connected not only with the increase in the amount of information in a geometrical progression, but also with the improvement of collecting methods, processing, storage and transmission. Intensive development of the global information network Internet continuously increases the number of its users.

Information revolution and rapid transformation of practically all types of activities, the emergence of a huge number of open and distance programs based on the Internet, the growth in demand in individually tailored competency packages instead of traditional diplomas and degrees, gamification and mass higher education, globalization and competition lead world educational systems in the state of stress requiring adequate responses.

For example, according to some researchers [1], export of educational services in the US economy brings in an average $\$ 13$ billion a year (the 5 th place among the export sectors of the economy US). A lot of countries claim that their GDP is based on the

Corresponding author: beketova@mti.edu.ru 
knowledge economy for $70-80 \%$. At the same time 1.5 exabytes of information were created in the world in 2008, which exceeds the previous 5000 years, and the world volume of knowledge since 2010 is doubled every 72 hours (3 days) [2].

\section{Influence on the quality of education}

There is a kind of expansion of on-line courses in the elite universities. World leading universities have joined the global experiment of reformatting of the educational services market. Students all over the world got an opportunity to listen to lectures by world famous leading experts. Now it is possible to allocate $[3,4]$, five largest in the world platforms of distance learning.

Non-profit educational organization Khan Academy, the purpose of which is "the provision of quality education to everyone, everywhere." The Academy Website provides access to more than 3,600 free lectures on mathematics, history, health, finance, physics, chemistry, biology, astronomy, economics and others.

- MOOC-platform Coursera is one of the most successful, it offers more than 420 training courses, has more than 80 partners and brings together more than 4.5 million students from around the world. The authors of courses are professors of world leading universities, including Princeton, Stanford, Columbia University.

- The non-profit project in the field of on-line-training edX offers free access to more than 60 courses, developed by the University of Berkeley, Austin, Georgetown, Harvard, MIT and others. In addition to the educational component, the founders of MOOCplatform has got an aim to research the learning efficiency.

- Educational company Linda.com, providing hundreds of on-line - trainings for getting of computer, design and business skills to achieve personal and professional goals. Service Linda.com includes about 2,500 training courses. The secret of success - to provide a large amount demanded on-line-trainings from dozens of existing professionals from various fields of activity.

Commercial educational organization Udacity offers about 30 courses, designed not only by university professors, but also by leading industry experts in such areas as computer science, design, mathematics, technology business. Each course offers several levels of difficulty - for beginners,intermediate and advanced students.

Globalization of education puts the universities before the realised need of distance education using distance technologies that meet the requirements of consumers of educational services.

Unlike Russia, in most Western countries, a form of distance learning has been recognized as an independent and promising direction for long, because it provides the possibility of combining professional activity and the process of obtaining vocational training. The global market of distance learning was assessed at $\$ 35.6$ billion in 2011. It is expected that by 2016 the market will grow to a volume of $\$ 51.5$ billion [5]. With the help of various technical devices the process of learning becomes personalized for the needs of the learner. It is in this form of training, it is possible to carry out individual training on a flexible schedule and by reducing the costs of the process of organizing, training programs are more beneficial in its affordable price.

In many ways, the changes taking place in higher education can be explained by demographic changes, reflected in the growth of the elderly, reducing the proportion of the working population and children and, therefore, changes in the structure of consumers of educational services. Today, the high rise of the number of freshmen growth is connected with the enrollment in higher schools older students, students receiving the second higher education and with practical experience in the professional field.

It is useless to fight with the objective tendencies, it is necessary to prepare to them and try to benefit from them.

It should be noted that the micro- and macroenvironment elements are identical, but they may have different dynamic, due to national characteristics.

For example, considering the processes of informatization, it should be noted that the shape of the national distance learning is belatedly integrated into traditional forms of various universities. And at the same time already existing domestic researches in the field of distance and e-learning does not just need to be processed, but require serious rethinking and completely new ways of presenting knowledge. Most of them built by the technique of traditional Russian education and innovations are made only in the placement of the materials on the web. The main global challenge of distance education is an artificial imposition of modern information technology to the traditional educational forms and the mismatch of the principles of the educational process to the current level of educational technologies. In this regard, it seems to us very important to extend the experience of teaching quality monitoring practiced in relation to traditional college and university educational systems, into the system of distance learning. Only in this case, it will really contribute to the improvement and modernization of higher education in our country.

A significant impact on the quality of educational services is provided by micro-environment. The growing commercialization of higher education, expressed in the growth of the number of students enrolled on a fee basis leads to ever greater differentiation of the applicants requirements to the quality of educational services. Today, scientists have identified three groups of students [6]. The first group consists of the students getting knowledge for future career development in a certain area. The group hopes to become professional in their field and therefore presents high demands to the content of training. In the second group there are students receiving occupation for which it is important to form outlook, to gain skills and abilities for future professional activity, and most important to learn how to replenish the knowledge, to be ready to make decisions and take responsibility for them independently. The third group is a group buying the environment, not concerned with the quality of educational services. 
Taking into account different training requirements, higher school should be ready to differentiate and individualize the model of the educational process.

While for the domestic market of educational services toughening price competition is characterized. We believe that with the improvement of life quality price competition will be replaced by quality competition and put more sharply the problem of defining their competitive advantages in the non-price aspect before the universities.

Even today, there are marketing intermediaries (consulting firms) that help higher education institutions to develop a rational strategy of their behavior in the market of educational services (at the same time increasing the number of educational business partners, requirements to the activity of universities).

As a result, the external environment has a direct, significant impact on the educational process, making the constant monitoring and searching for methods of adaptation to its changes quite necessary.

At the same time the internal environment of higher school, which determines the capacity of the latter in the field of education quality, is also the subject for constant changes. The quality of education is largely determined by the degree of implementation of the federal state educational standards and basic vocational and educational programs developed by the university, the curriculum, its interdisciplinary connections as well . It is important that the curriculum allows you to realize the developed competence model of specialist training, based on the totality of traditional and interactive method, teaching aids in practice .

No less important internal factor that determines the quality of education is higher school human resources. Undoubtedly the level of professionalism, knowledge of modern methods and means of education directly affects the quality of educational services. A modern teacher is a kind of the manager, who is able to organize students into an effective and focused group or a work team; the manager who not only knows how to set goals and choose the methods to achieve them, but also effectively organizes the activities using the methods of engagement and motivation, control, methods of evaluation and correcting actions. This also should include binding processes: communication (exchange of information with the students) and decision-making, as well as the style of the leading activity, different ways of influencing students. The application of these means is a far more difficult task than deep knowledge of their subject area, although the latter is the most important factor and indispensable attribute of any teacher.

The productive capacity is also important, since the technology does not come without means of training (without space, equipment, classrooms, offices, laboratories, computer and other office equipment, local networks and global computer networks). The lack of modern technological base (equipment, used on specific jobs, the inability to complete the organization of practical training in enterprises) in the training of qualified personnel can become one of the main moments, making Russian education incompetitive with the level of preparation in other countries. If graduates has no practice or skills, they are unable to work with modern materials and equipment.

Ministry of Education has defined the criteria for monitoring the whole Russian education system, including indicators that determine the logistical and information support of educational institutions, including:

- Provision of students with dormitories (the proportion of students living in dormitories in the total number of students who need hostels);

- Provision of students with a network of catering;

- The number of personal computers used for teaching purposes, per 100 students;

- The proportion of the number of organizations having an access to the Internet at a speed of data transmission of $2 \mathrm{Mbit} / \mathrm{s}$ and above, the total number of educational institutions connected to the Internet;

- The square of learning and laboratory buildings per student.

So far only principles of logistics in educational institutions are outlined. In the future, it is expected to define specific indicators and their meanings.

Undoubtedly the increase in the contingent of students without building and renewal of main stocks, which higher education have, can lead to a decrease in the quality of education. In the research conducted by the British company Quacquarelli Symonds in 2014, more than 700 universities all over the world, among them 21 Russian ones, took part. In the top-200 there is only one Russian university, Moscow State University, which is on the 114th place [7]. The material and technical base of educational institutions is playing an important role for entering the ranking of the best universities of the world. So, the question about what material and technical base the university should have to provide quality training for their students, remains open in both the theoretical and practical plans.

Developing by universities the quality management systems have significant impact on the quality of education. In Russia and abroad three basic models are mainly used: estimated method of quality management of the university activity; management based on the principles of Total Quality Management (TQM); approach based on the requirements of the international ISO quality management standards. However, in practice, quite often there is a situation when the management of educational institution can not reconcile two fundamental objectives - ensuring the quality of educational services and strategic quality management. In such cases, the absence of modern approaches to adapt the experience of quality management system to the educational organization leads to the formalization of the process and complication, the duplication, the bureaucratization of the entire university management system instead of the expected effective management.

In turn, the assessment the prospects of the achievement of high competitiveness based on the definition of the types and forms of activity, the priority development which can provide the necessary breakthrough. At the same time saving the lines of development that today determine the attractive image of 
the university, having become its recognized traditions, is important.

In our opinion, current reforms in the system of higher education in Russia and the reduction of public funding of the education sector define the situation in which you need to find a balance between the process of ensuring the quality of educational activities and financial viability. Strategies of achieving the objectives of this kind, in our view, must comply with the mechanism of financial planning and budgeting in order to reduce operating costs with the most effective and efficient way to optimize the allocation of resources and to ensure the management with financial losses. The resolution of these strategic objectives to a greater extent is also due to the fact, how an educational institution can increase its income, bringing to the market innovative educational products and services. Both for industrial corporations and universities the main method of finding new sources of finance is to enter new markets. For universities it is firstly a market of paid education, as well as market scientific researches and innovations nowadays.

\section{Conclusion}

Formation of the new priorities while maintaining the continuity of the activities is to provide high school adaption to the demands of a changing social and economic environment. Choosing the best ways to organize the work of the university in the new conditions, taking into account the observed trends in development, including the use of all resources for an effective response to the significant changes is the main task of strategic management. And taking into account modern trends occurring in the external and internal environment, higher education must move to projectbased learning on topical issues and gradually turn into a "factory start-ups," to become a platform of innovative entrepreneurial experiments [8]. At the same time priorities of this institution should be training, retraining, raising staff qualifications and development of scientific and technical solutions for the innovative development of regions and countries. Carrying out high-level researches in their respective fields of science and technology is the key to high quality and relevance of educational services.

\section{References}

1. A.L. Andreev, Russia in the global educational space. Higher education in Russia, 12, 9-20 (2009)

2. N.V. Tikhomirov, Legislative and regulatory and legal support for the e-learning industry for intensive development of the Russian economy. Economics and education today, 19 (2010)

3. I.A. Press, Integration of classical and information technology as a pedagogical basis for the modernization of the modern educational system, $\mathrm{V}$ International Congress The role of business in the transformation of the Russian society of 2010, 496498 (2010)

4. L.V. Bobrova Problems of integration of pedagogical and information technologies. Actual problems of the humanities and natural sciences. 12(2), 58-60 (2014)

5. E Learning Market Trends \& Forecast 2014- 2016. (A report by Docebo, 2014).

6. A. Livandovkaya, External and internal environment of high school: the impact on the quality of education. Higher education in Russia, 7, 152-155 (2006)

7. http://ria.ru/society/20140916/1024253804.html

8. A.V. Belotserkovskii, Universities as generators of regional development. Higher education in Russia, 1, 5-10 (2015). 